\title{
Effect of Lidocaine in Acute Ischemic Situations: A Computer Modelling Study
}

\author{
K Cardona ${ }^{1}, \mathrm{~J} \mathrm{Saiz}^{1}, \mathrm{JM}(\mathrm{Jr})$ Ferrero $^{1}, \mathrm{M} \mathrm{Martinez}^{2}$, \\ $\mathrm{G} \mathrm{Molto}^{3}$, V Hernandez \\ ${ }^{1}$ Center for Research and Innovation on Bioingineering, UPV, Valencia, Spain \\ ${ }^{2}$ Grupo Predictive Control and Heuristic Optimization Research Group, UPV, Valencia, Spain \\ ${ }^{3}$ High Performance Networking and Computing Group, UPV, Valencia, Spain
}

\begin{abstract}
Lidocaine is a drug that blocks the sodium channel in a $\mathrm{pH}$, frequency and concentration dependent manner. In this work, we have used a mathematical model of lidocaine developed by our group and incorporated it into the Luo Rudy model of ventricular action potential. We have studied the action of lidocaine on the sodium current $\left(I_{N a}\right)$, maximum upstroke velocity $(d V / d t)$ and conduction velocity (CV) in ischemic tissue. Additionally, we measured the block window $(B W)$ in different concentrations of drug. Our results show that $100 \mu \mathrm{mol} / \mathrm{L}$ of lidocaine under simulated acute ischemic conditions reduces the $I_{\mathrm{Na}}, d V / d t$ and $C V$ a $42 \%, 41 \%$ and $24 \%$ in the normal zone (cell 54), respectively while in the border zone (cell 94) the decreased was $37 \% ; 44 \%$ and $18 \%$ for the same parameters. Finally, we have found that lidocaine diminished de $B W$, thus the drug tends to eliminate the $U D B$.
\end{abstract}

\section{Introduction}

Lidocaine is a class Ib antiarrhytmic drug that blocks the sodium channels. The blockade of these channels produces a decrease in the sodium current $\left(\mathrm{I}_{\mathrm{Na}}\right)$ as a result of it reduction the conduction velocity $(\mathrm{CV})$ is diminished too $[1,2]$. The actions of lidocaine on the sodium channel are a dose and use dependent manner

The possible mechanism for drug-associated arrhythmogenesis could be related with the delayed recovery of cellular excitability which can introduce a nonuniform dispersion of refractoriness along the cardiac fiber and could serve as a substrate for initiating reentrant rhythms [3]. Carsson has proposed that the failure in the propagation can favour a unidirectional block of wave front of the stimuli $[4,5]$.

Under ischemic conditions the action of lidocaine is modified. The substantial fall in external $\mathrm{pH}$ during myocardial ischemia changes the kinetics of drug binding to the $\mathrm{Na}^{+}$channel and may explain the more depressant effect of these drugs during myocardial ischemia [6]. A study has found that the kinetics of recovery from lidocaine were increased and slowed when the extracellular $\mathrm{pH}$ was reduced $[7,8]$.

On the other hand, the mechanism by which drugs like lidocaine suppresses o exerts arrhythmic effect is still not well understood. Some experiments have shown that the reduction of excitability promotes the proarrhythmic effect and in ischemic conditions its action is increased due to dispersion of the conduction [9-11]. However, limited studies have demonstrated that lidocaine can prevent arrhythmias as a result of its ability to prolong the refractoriness [12].

To understand the nature of this paradox, we first explore the action of lidocaine on the characteristics on action potential (sodium current $\left(\mathrm{I}_{\mathrm{Na}}\right)$, maximum upstroke velocity $(\mathrm{dV} / \mathrm{dt})$ and conduction velocity $(\mathrm{CV}))$ in ischemic tissue. And then, we studied the effect of lidocaine on the block window (BW) defined as the range of delays between the premature stimuli can not propagate around all tissue.

\section{Methods}

We use the mathematical model of lidocaine developed previously by our group where it is included the $\mathrm{pH}$ and use dependent. This model is based in the guarded receptor hypothesis (GRH) and the binding and unbinding process is assumed as a hydrophobic process, a hydrophilic process, and a coupling of charged and neutral blocked channels with a proton exchange process [13].

Additionally, we have used the Luo Rudy model (LRd00) of guinea pig ventricular cells in order to modelling the electrical activity of myocardial [14].

The simulated tissue was composed of a strand of 370 cells in acute ischemic conditions. To introduce the heterogeneity produced by acute ischemia, we have simulated three main components: hiperkalemia (increase in the extracellular $\mathrm{K}^{+}$concentration $\left(\left[\mathrm{K}^{+}\right]_{\mathrm{o}}\right)$ ), hypoxia (activation of the K[ATP] current) and acidosis 
(reduction in the availability of $\mathrm{Na}^{+}$and $\mathrm{Ca}^{+}$channels) $[15,16]$.

We have assumed that the lidocaine should be able to get in of the ischemic zone the same degree as potassium can get out of the ischemic zone.

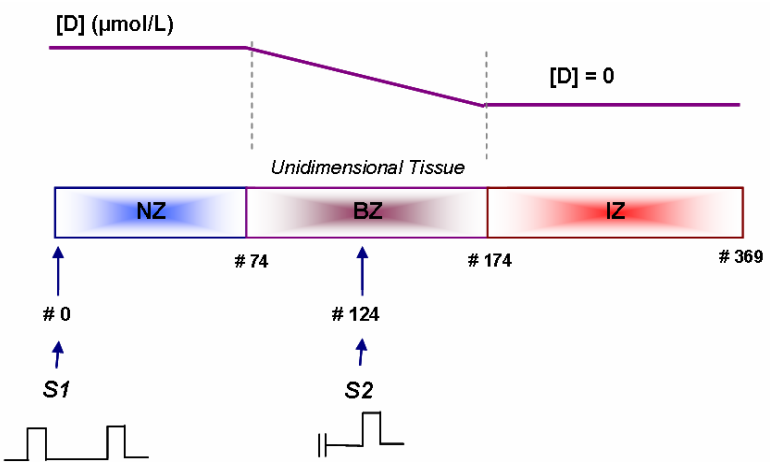

Figure 1. Schematic of unidimensional tissue under ischemic conditions.

The excitation was applied to cell \# 0 , and the action potential characteristics were measured in the different zones of the tissue when the steady-state was reached as shown in figure 1 . We tested the effect of different lidocaine concentrations on the sodium current $\left(\mathrm{I}_{\mathrm{Na}}\right)$, maximum upstroke velocity $(\mathrm{dV} / \mathrm{dt})$ and the conduction velocity $(\mathrm{CV})$. In order to explore the cell excitability, we used the concept of the block window (BW), which was obtained with the protocol S1-S2. A basic stimulus (S1) of $500 \mathrm{~ms}$ cycle length (BCL) with pulse duration of $2 \mathrm{~ms}$ has been used and the premature pulse (S2) was applied at a different location from the basic stimulus (cell \# 124).

\section{Results and discussion}

Initially, we measured the effect of different concentrations of lidocaine on $\mathrm{I}_{\mathrm{Na}}, \mathrm{dV} / \mathrm{dt}$ and $\mathrm{CV}$ for $\mathrm{BCL}$ of 200 and $500 \mathrm{~ms}$ under ischemic conditions. In the figure 2, we can observe the reduction on $\mathrm{I}_{\mathrm{Na}}$ in the different zones of the tissue.

In the normal zone (cell \# 54), the $\mathrm{I}_{\mathrm{Na}}$ was decreased a $42 \%$ for $100 \mu \mathrm{mol} / \mathrm{L}$ of lidocaine. In the border zone, the decrease in the cell 94 was a $37 \%$, whereas in the cell 174 , it was a $1 \%$. Finally, the $\mathrm{I}_{\mathrm{Na}}$ was unaffected at the ischemic zone.

When we varied the BCL under ischemic conditions, the action of lidocaína on $\mathrm{I}_{\mathrm{Na}}$ was modulated, so if we decreased the BCL the reduction was increased. In normal tissue, in presence of $100 \mu \mathrm{mol} / \mathrm{L}$ lidocaine the $\mathrm{I}_{\mathrm{Na}}$ was reduced a $54 \%$ and $41 \%$ for BCL of 200 and $500 \mathrm{~ms}$, respectively. In the border zone, the decline was of $48 \%$ and $36 \%$ for the same BCLs.

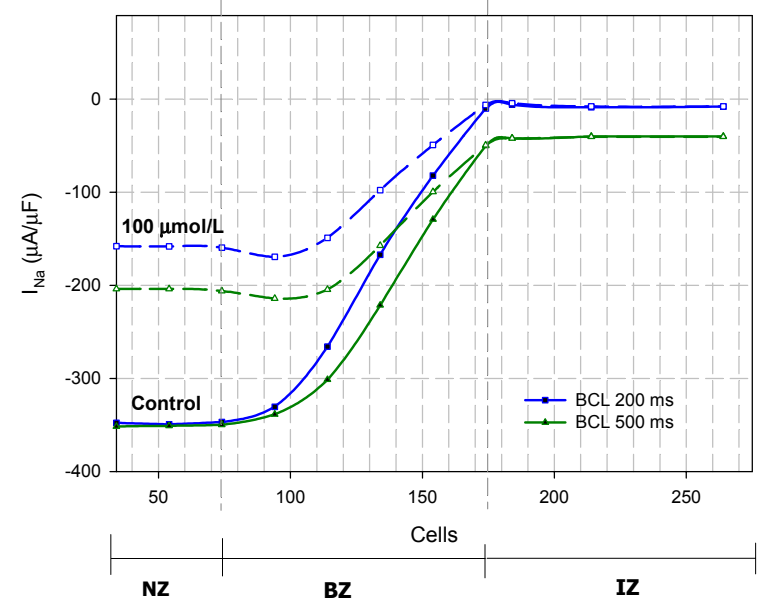

Figure 2. Effect of $100 \mu \mathrm{mol} / \mathrm{L}$ (dashed line) lidocaine on the $\mathrm{I}_{\mathrm{Na}}$ and in absence of the drug (solid line) in different cells for a BCL of $200(\boldsymbol{\square})$ and $500 \mathrm{~ms}(\boldsymbol{\Delta})$.

In respect to the $\mathrm{dV} / \mathrm{dt}$, we found the same effects that the sodium current, the reduction on $\mathrm{dV} / \mathrm{dt}$ was higher at the normal zone than at the ischemic. In our results we have obtained that in the normal zone the $\mathrm{dV} / \mathrm{dt}$ was decreased $20 \%, 36 \%$ and $50 \%$ for the concentrations of 20,50 and $100 \mu \mathrm{mol} / \mathrm{L}$ of lidocaína, respectively. We can observe this effect in the table 1 .

\begin{tabular}{|c|c|c|c|c|}
\hline \multicolumn{5}{|c|}{ dV/dt (\%) } \\
\hline & & \multicolumn{3}{c|}{ Concentration of drug ( $\mathbf{\mu m o l} / \mathbf{L})$} \\
\hline & Cell & 20 & 50 & 100 \\
\hline NZ & 54 & 20 & 36 & 50 \\
\hline \multirow{2}{*}{ BZ } & 74 & 19 & 35 & 49 \\
\cline { 2 - 5 } & 134 & 10 & 21 & 34 \\
\hline IZ & 194 & 0.7 & 4 & 4.5 \\
\hline
\end{tabular}

Table 1. Effect of different concentrations of lidocaine on $\mathrm{dV} / \mathrm{dt}$ in the several zones of the ischemic tissue

Additionally, the action of lidocaine on CV was increased when we grow up the concentration. In the figure 3 , we show the effect of lidocaine on $\mathrm{CV}$ in the different zones of the tissue. In the normal zone, the reduction was similar for all cells whereas in the border zone the reduction depends on the considered cell, in the middle of the zone there is an increase in the value of CV which is maintained in the presence of lidocaine.

We found few studies where the action of lidocaine on the characteristics of action potential was evaluated. However, our results were consistent with experimental recordings where is expressed the dispersion on the $\mathrm{CV}$ when the ischemic conditions and the drug were mixed. $[17,18]$. 


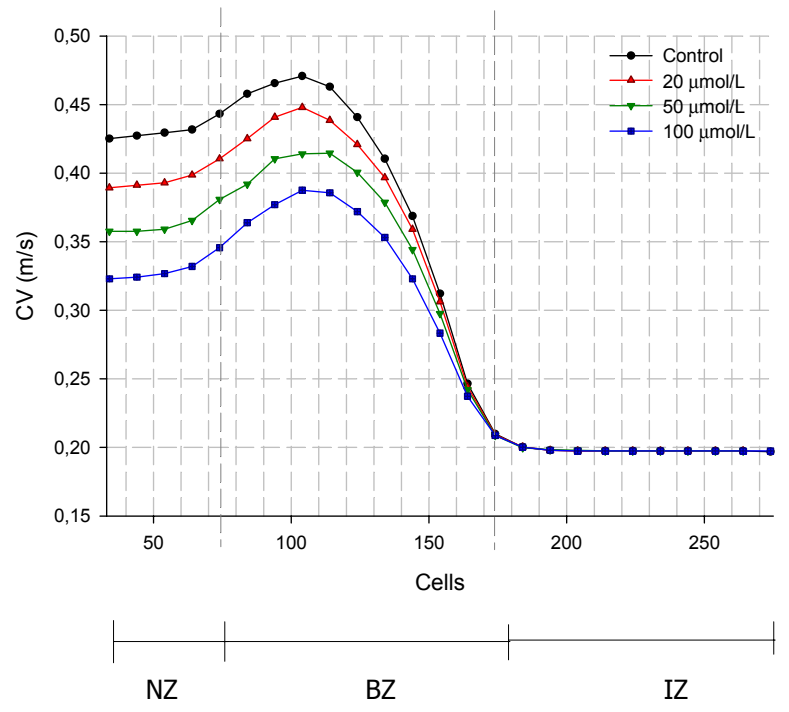

Figure 3. Effect of different concentration of lidocaine on

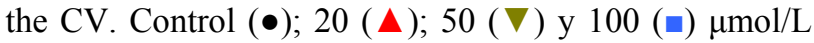
lidocaine.

It is well known that slow conduction and unidirectional block (UDB) set the stage for reentry after a premature stimulation. Our previous results have demonstrated that lidocaine changes the CV. For this reason, we explore the effect of drug on excitability under ischemic conditions through the concept of block window $(\mathrm{BW})$. We used the protocols $\mathrm{s} 1-\mathrm{s} 2$, the basic stimulation was applied in the cell 0 . To the stimuli premature (s2) we applied in cell 124 . We obtained the limits of the BW varied the coupling interval (CI).

With this protocol, we found three pattern of activation: no propagation (the tissue was still refractoriness state and the stimuli premature can not propagate), UDB and complete propagation.
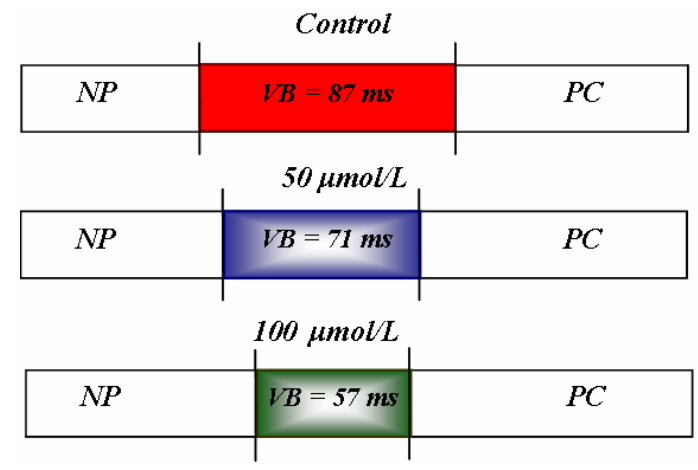

Figure 4. Width of the block window for different concentrations of lidocaine.

In the figure 4 shows the $\mathrm{BW}$ and its superior and inferior limits obtained for a control, 50 and $100 \mu \mathrm{mol} / \mathrm{L}$ of lidocaine.

In absence of drug we have found a BW around $87 \mathrm{~ms}$ while, with 50 and $100 \mu \mathrm{M}$ lidocaine the BW was 71 and $57 \mathrm{~ms}$, respectively. Additionally, we have observed that the two limits were modulated in presence of both concentrations of drug due to the action of lidocaine on the slow CV and the effective refractory period. Table 2 shows the values for the limits and BW founded.

\begin{tabular}{|c|c|c|c|c|}
\hline $\begin{array}{l}\text { Concentrations } \\
(\boldsymbol{\mu m o l} / \mathbf{L})\end{array}$ & $\begin{array}{l}\text { IL } \\
(\mathbf{m s})\end{array}$ & $\begin{array}{l}\text { SL } \\
(\mathbf{m s})\end{array}$ & $\begin{array}{l}\text { BW } \\
(\mathbf{m s})\end{array}$ & $\begin{array}{l}\text { BW } \\
(\mathbf{\%})\end{array}$ \\
\hline 0 & 155 & 242 & 87 & \\
\hline 50 & 163 & 234 & 71 & 18 \\
\hline 100 & 173 & 230 & 57 & 34 \\
\hline
\end{tabular}

Table 2. Values for the inferior (IL) and superior (SL) limit, block window (BW) in different concentrations of lidocaine under simulated acute ischemic conditions.

\section{Conclusions}

In conclusion, our simulations have shown that the action of lidocaine on the $\mathrm{I}_{\mathrm{Na}}, \mathrm{dV} / \mathrm{dt}$ and $\mathrm{CV}$ under ischemic conditions depend on the zone of the tissue. As well as, we can observe that the blockade in all zones of the tissue is frequency dependent when the tissue is modified for the acute ischemia. Furthermore, our simulations are consistent with experimental observations where the lidocaine and acute regional ischemic modulate the dispersion of the $\mathrm{CV}$ due to different action on the diverse zones of the ischemic tissue.

Finally, we have observed that the BW was decreased for the different concentrations of the drug studied. Therefore, we can say that lidocaine reduces the start of UDB, thus it could be an antiarrhythmic effect of drug.

\section{Acknowledgements}

This work was partially supported by the Plan Nacional de Investigación Científica, Desarrollo e Innovación Tecnológica del Ministerio de Educación y Ciencia of Spain (TEC2005-04199).

\section{References}

[1] Clarkson CW, Matsubara T, Hondeghem LM. Evidence for voltage-dependent block of cardiac sodium channels by tetrodotoxin Conductance and kinetics of delayed rectifier potasium channels in nodal cells of the rabbit heart Tratado de fisiología médica. J Mol Cell Cardiol 1988; 20(12):1119 3703-1131.

[2] Anderson KP, Walker R, Lux RL, Ershler PR, Menlove R, Williams MR et al. Conduction velocity depression and drug-induced ventricular tachyarrhythmias. Effects of lidocaine in the intact canine heart 3. Circulation 1990; 81(3):1024 3703-1038.

[3] Starmer CF. The role of intrinsic and induced vulnerability 
in electrically induced cardiac arrhythmias. J Cardiovasc Electrophysiol 2006; 17(12):1369-1370

[4] el Sherif N, Scherlag BJ, Lazzara R, Hope RR. Re-entrant ventricular arrhythmias in the late myocardial infarction period. 4. Mechanism of action of lidocaine 2. Circulation 1977; 56(3):395 3703-402.

[5] Carson DL, Cardinal R, Savard P, Vasseur C, Nattel S, Lambert $C$ et al. Relationship between an arrhythmogenic action of lidocaine and its effects on excitation patterns in acutely ischemic porcine myocardium 4. J Cardiovasc Pharmacol 1986; 8(1):126 3703-136

[6] Kupersmith J, Antman EM, Hoffman BF. In vivo electrophysiological effects of lidocaine in canine acute myocardial infarction 2. Circ Res 1975; 36(1):84 3703-91.

[7] Grant AO, Strauss LJ, Wallace AG, Strauss HC. The influence of $\mathrm{pH}$ on th electrophysiological effects of lidocaine in guinea pig ventricular myocardium Conductance and kinetics of delayed rectifier potasium channels in nodal cells of the rabbit heart Tratado de fisiología médica. Circ Res 1980; 47(4):542 3703-550.

[8] Broughton A, Grant AO, Starmer CF, Klinger JK, Stambler BS, Strauss HC. Lipid solubility modulates $\mathrm{pH}$ potentiation of local anesthetic block of Vmax reactivation in guinea pig myocardium 3. Circ Res 1984; 55(4):513 3703-523.

[9] Nesterenko VV, Lastra AA, Rosenshtraukh LV, Starmer CF. A proarrhythmic response to sodium channel blockade: modulation of the vulnerable period in guinea pig ventricular myocardium 5. J Cardiovasc Pharmacol 1992; 19(5):810-820.

[10] Li GR, Ferrier GR. Effects of lidocaine on reperfusion arrhythmias and electrophysiological properties in an isolated ventricular muscle model of ischemia and reperfusion 1. J Pharmacol Exp Ther 1991; 257(3):997 3703-1004

[11] Yin H, el Sherif N, Caref EB, Ndrepepa G, Levin R, Isber $\mathrm{N}$ et al. Actions of lidocaine on reentrant ventricular rhythms in the subacute myocardial infarction period in dogs 2. Am J Physiol 1997; 272(1 Pt 2):H299 3703-H309.

[12] Cardinal R, Janse MJ, van E, I, Werner G, d'Alnoncourt $\mathrm{CN}$, Durrer D. The effects of lidocaine on intracellular and extracellular potentials, activation, and ventricular arrhythmias during acute regional ischemia in the isolated porcine heart 3. Circ Res 1981; 49(3):792-806.

[13] Starmer CF, Courtney KR. Modeling ion channel blockade at guarded binding sites: application to tertiary drugs Conductance and kinetics of delayed rectifier potasium channels in nodal cells of the rabbit heart Tratado de fisiología médica. Am J Physiol 1986; 251(4 Pt 2):H848 3703-H856.

[14] Luo CH, Rudy Y. A dynamic model of the cardiac ventricular action potential. I. Simulations of ionic currents and concentration changes Conductance and kinetics of delayed rectifier potasium channels in nodal cells of the rabbit heart Tratado de fisiología médica. Circ Res 1994; 74(6): 1071 3703-1096.

[15] Coronel R, Fiolet JW, Wilms-Schopman FJ, Schaapherder AF, Johnson TA, Gettes LS et al. Distribution of extracellular potassium and its relation to electrophysiologic changes during acute myocardial ischemia in the isolated perfused porcine heart 2 . Circulation 1988; 77(5):1125 3703-1138.

[16] Ferrero JM, Trénor B, Rodriguez B, Sáiz J. Electrical activity and reentry during acute regional myocardial ischemia: insights from simulations. International Journal of Bifurcation and Chaos 2003; 13(12):3703-3715.

[17] Campbell TJ, Hemsworth PD. Selective depression of maximum rate of depolarization of guinea-pig ventricular action potentials by amiodarone and lignocaine in simulated ischaemia: comparison with encainide 1. Clin Exp Pharmacol Physiol 1990; 17(2):135 3703-145.

[18] Restivo M, Yin H, Caref EB, Patel AI, Ndrepepa G, Avitable MJ et al. Reentrant arrhythmias in the subacute infarction period. The proarrhythmic effect of flecainide acetate on functional reentrant circuits 6. Circulation 1995; 91(4):1236-1246.Type your references here. With the reference style, numbering is supplied automatically.

Address for correspondence

Karen Cardona Urrego

Instituto de Investigación e Innovación en Bioingeniería, UPV Valencia- Spain

E-mail: kacarur1@doctor.upv. 